\title{
Ecosystem model of the western Wadden Sea: a bridge between science and management?*+
}

\author{
H. J. Lindeboom, W. van Raaphorst, H. Ridderinkhof \& \\ H. W. van der Veer
}

Netherlands Institute for Sea Research; P.O. Box 59, 1790 AB Den Burg-Texel, The Netherlands

\begin{abstract}
This paper describes the construction, validation and application of a mathematical ecosystem model of the western Wadden Sea. This model is based upon the Ems-Dollard ecosystem model, but also includes a two-dimensional transport submodel, a benthic and epibenthic sublitoral submodel and nutrient regeneration. In 1986, an extensive field programme was executed to collect data for model validation. Apart from the subtidal processes the validation indicates that the model simulates the different state variables reasonably well. The applicability of the model for management purposes was tested in four case studies concerning: dredging activities, eutrophication, commercial mussel culture and oil spills and other calamities. It is concluded that the western Wadden Sea model in general is a useful tool in evaluating the impact of certain anthropogenic activities in the area.
\end{abstract}

\section{INTRODUCTION}

This article is a brief outline of the Dutch report "Ecosysteemmodel van de westelijke Waddenzee" (EON-projectgroup, 1988), which together with the publications in the Netherlands Journal of Sea Research 22/1 (1988) forms the final report of the project "Ecological model research of the western Wadden Sea (EMOWAD)". The project, commissioned by four Dutch ministries, was carried out between 1984 and 1987 at the Netherlands Institute for Sea Research (NIOZ, Texel) and the department of Marine Biology at the State University of Groningen.

Two problems formed the central theme in the project: firstly the managers of the Wadden Sea felt the need for an integration of the results of the ecological studies which had been carried out in this area in the past; secondly, the managers felt that the existing knowledge was too inaccessible. Therefore, the aims of the project were the following: - To gain insight into the structure and the functioning of the living communities in the western Wadden Sea, in order to get a qualitative and if possible quantitative description of the occurrence of and the connection between different groups of organisms in this ecosystem.

- To trace and describe the factors which on the one hand may lead to changes in the

\footnotetext{
- Presented at the VI International Wadden Sea Symposium (Biologische Anstalt Helgoland, Wattenmeerstation Sylt, D-2282 List, FRG, 1-4 November 1988)

+ Publication no. 7 Applied Scientific Research NIOZ (BEWON)
} 
present structure and/or functioning of the ecosystem, and on the other hand can be influenced by human activity.

- To indicate on the basis of the knowledge described above to what extent specific human activities (e.g. pollution, fisheries etc.) may influence the ecology of the western Wadden Sea.

These aims were to be achieved by putting to optimal use the knowledge on the area, collected by the NIOZ and by employing the knowledge and experience gained during the modelling research in the Ems-Dollard estuary (Baretta \& Ruardij, 1988).

Based upon this, a mathematical ecosystem model was considered an important tool to meet the aims set above. The Ems-Dollard model (Baretta \& Ruardij, 1988) was used as a basis for this western Wadden Sea project, but due to the difference in properties between the Ems-Dollard and the western Wadden Sea some important changes were required: first, instead of a one-dimensional, a two-dimensional transport part of the model was needed; secondly, because of morphological differences, the model was expanded with a benthic and an epibenthic sublittoral part; and thirdly, nutrient regeneration ( $\mathrm{P}$ and $\mathrm{Si}$ ) was introduced into the model. In the different chapters of the EMOWAD I report (EON-projectgroup, 1988), the successes and failures of these adaptations are described; applications of the model to management purposes are also given. The following paper summarizes this report.

\section{ADJUSTMENTS AND EXTENSIONS TO THE ECOSYSTEM MODEL}

The western Dutch Wadden Sea differs from the Ems-Dollard estuary mainly in the higher complexity of its geometry and morphology. An important morphological difference is that shallow subtidal regions cover more than 50 percent of the western Wadden Sea while the subtidal regions in the Ems-Dollard cover so small an area as to be negligible. The subtidal biomass was not included in the Ems-Dollard model. Since the benthic biomass in these subtidal areas forms a substantial part of the total biomass (Dekker, 1987), a specific (epi)benthic submodel for this region has been included. Thus, the EMOWAD model has a separate submodel for simulating carbon flows in the (epi)benthic community of the subtidal. The structure of these new submodels is identical to the submodel for the (epi)benthic community on the tidal flats. Except for the benthic suspension feeders, the modelling of functional groups or state variables (Table 1) is also the same in both areas.

Another difference between the western Wadden Sea and the Ems-Dollard is to be found in the complexity of the geometry. The western Wadden Sea consists of two connected tidal basins, and is therefore connected with the adjacent North Sea by two tidal inlets. Furthermore, the channel system in these basins is rather irregular and far more complicated than the more simply shaped Ems-Dollard estuary. For these reasons, the transport part of the model, including the module describing the transport of suspended matter, was made two-dimensional, A direct consequence of this two-dimensionality is that parameters in this tidally averaged box-model cannot be computed from observed salinity distributions during stationary periods. A two-dimensional hydrodynamical model (Ridderinkhof, 1988) has been used to determine these parameters, e.g. residual transports and exchange coefficients between the compartments of the EMOWAD model. Computations with the hydrodynamical model showed that there is a 
Table 1. Description of the most important state variables used in the ecosystem model of the western Wadden Sea. The state variables marked with an asterisk were validated

\begin{tabular}{|c|c|}
\hline Pelagic submodel & Benthic and epibenthic submodel \\
\hline Pelagic diatoms* & Benthic diatoms \\
\hline Phytoplankton other than diatoms ${ }^{*}$ & Bacteria aerobic layer \\
\hline Pelagic bacteria* & Bacteria anaerobic layer \\
\hline Microzooplankton & Meiobenthos* \\
\hline Pelagic mesozooplankton * & Benthic deposit feeders* \\
\hline Chlorophyl-a* & Benthic suspension feeders* \\
\hline Total primary production ${ }^{*}$ & Meso-epibenthos* \\
\hline Particulate organic carbon & Macro-epibenthos* \\
\hline Labile organic carbon & Chlorophyl-a in top $0.5 \mathrm{~cm}^{*}$ \\
\hline Detritus & Labile org. $\mathrm{C}$ in aerobic layer \\
\hline Refractory organic carbon & Detritus in aerobic layer \\
\hline Dissolved organic carbon & Labile org. $\mathrm{C}$ in anaerobic layer \\
\hline Total suspended matter* & Detritus in anaerobic layer \\
\hline Pelagic bacterial production* & Refractory organic carbon \\
\hline Total oxygen consumption * & Sulphide in anaerobic layer \\
\hline Dissolved reactive phosphorus" & Pyrite in anaerobic layer \\
\hline Dissolved reactive silicate ${ }^{*}$ & $\begin{array}{l}\text { Total inorganic reactive } \mathrm{P} \text { in aerobic layer } \\
\text { Total inorganic reactive } \mathrm{P} \text { in anaerobic layer } \\
\text { Benthic community repiration }\end{array}$ \\
\hline
\end{tabular}

large-scale tidally driven residual flow through both basins, directed from the northern towards the southern inlet. For the EMOWAD model, it has been assumed that the residual transport between these compartments is a combination of this tidally driven residual flow and the residual flow caused by the supply of fresh water from the Lake IJssel. Figure 1 gives these total transports over a representative period.

Exchange coefficients have been determined by computing trajectories of water masses in our hydrodynamical model. The computed volume of water exchanged between adjacent compartments over a tidal period has been used for determining the different values of this parameter.

A general extension to the model is the explicit modelling of regeneration of $\mathrm{P}$ and $\mathrm{Si}$. Pelagic regeneration of $P$ is simply modelled with a constant ratio between mineralized organic $\mathrm{C}$ and regenerated $\mathrm{P}$. It has been assumed that the regeneration of $\mathrm{Si}$ is a relatively slow process which mainly takes place in the sediment.

The formula for benthic regeneration is based on the assumption that the rates of the processes concerned and the concentration in the overlying water change slowly compared to the time needed to achieve steady state profiles in the pore water. Consequently, the formulae refer to pseudo-stationary conditions. This assumption as well as the derivation of the equations, is described in detail by van Raaphorst et al. (1988). Some new parameters which are related to the explicit modelling of Si and $\mathrm{P}$ in the (an)aerobic layer have been introduced, including diffusion coefficients, chemical reaction rates and parameters describing the precipitation/dissolution ( $\mathrm{Si}$ ) and the adsorption/desorption ( $\mathrm{P}$ ) equilibrium concentrations. The coupling of P-production to degradation of organic matter due to mineralization is modelled via a stoichiometric relation. The values of 


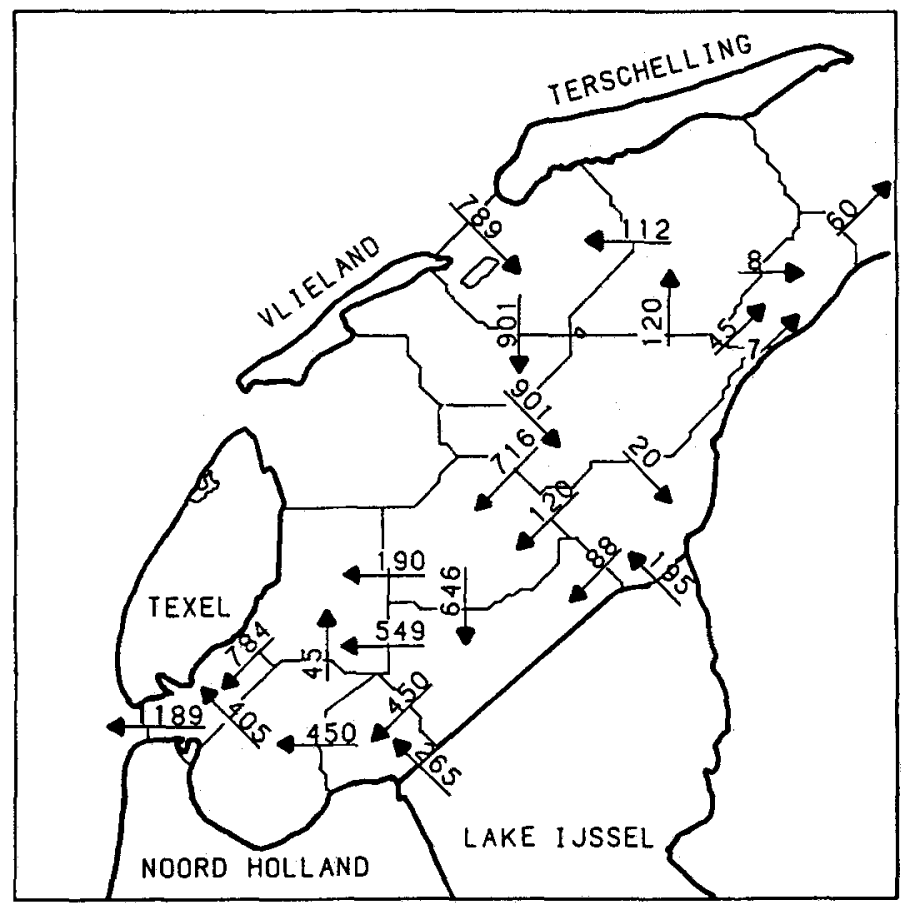

Fig. 1. Residual transport $\left(\mathrm{m}^{3} \cdot \mathrm{s}^{-1}\right)$ between the EMOWAD compartments during a period with a representative supply of fresh water from Lake UJsel

parameters connected to this modelling of nutrient regeneration have been so chosen that fluxes of Si and P agree with reported measurements (van Raaphorst et al., 1988).

\section{MODEL VALIDATION}

A validation of the model has been performed by comparing for each compartment the simulation results for 1986 with field-data of the same year. For the calibration procedure, simulations and data concerning 1979 and 1985 were used. For each variable to be evaluated three criteria were used for the validation. The first indicates whether the mean difference between the field data and the corresponding simulation points is acceptable. The simulation is judged to be good when this difference is smaller than $20 \%$, and bad when it is larger than $50 \%$ of the field data. The second criterion indicates to which extent the annual mean values of data and simulation points coincide, while the third gives information on the accuracy of the form of the simulation (seasonal pattern). One has to realize that the validity of field data is often questionable. These data are not free of errors, and represent only single points in time and space, while the model output gives mean values for larger areas. This means that the validation of the model is based on qualitative rather than quantitative aspects. Nevertheless, the more data available to validate each variable, the more the results of the validation may be interpreted quantitatively. 

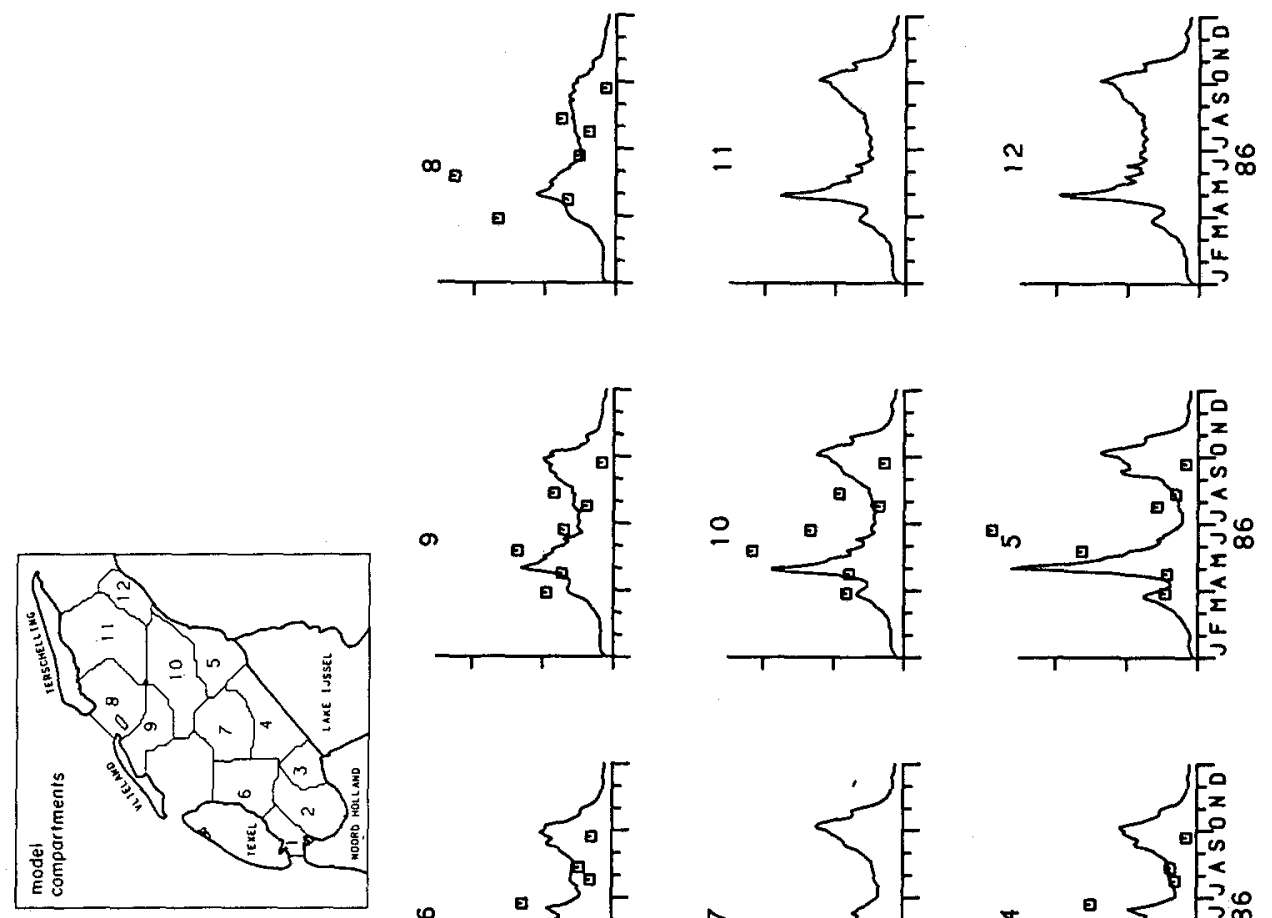

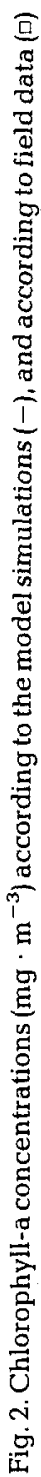
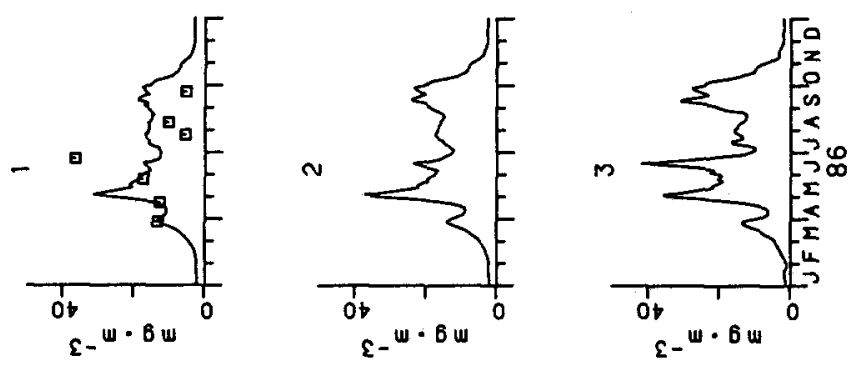

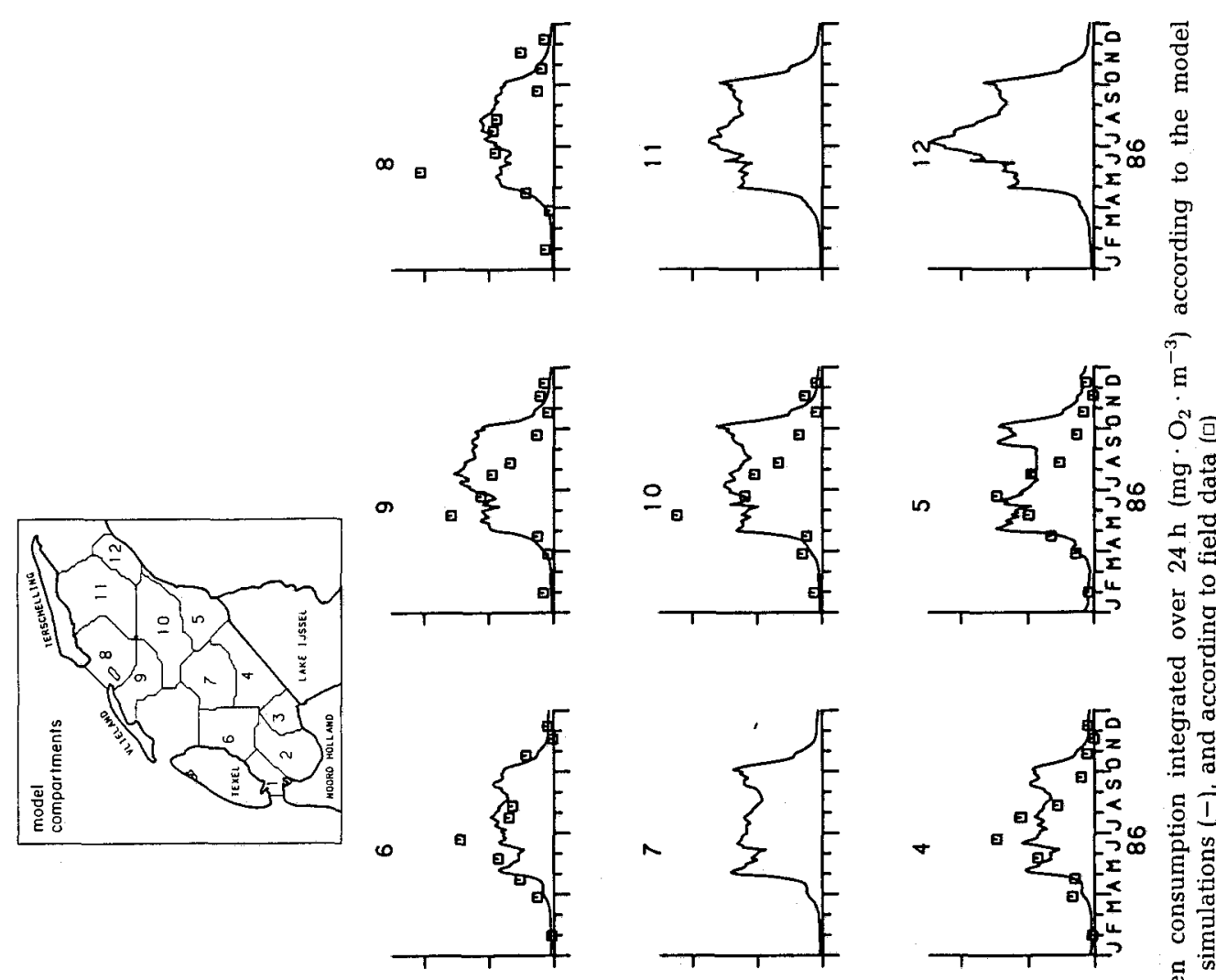

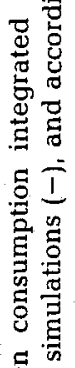
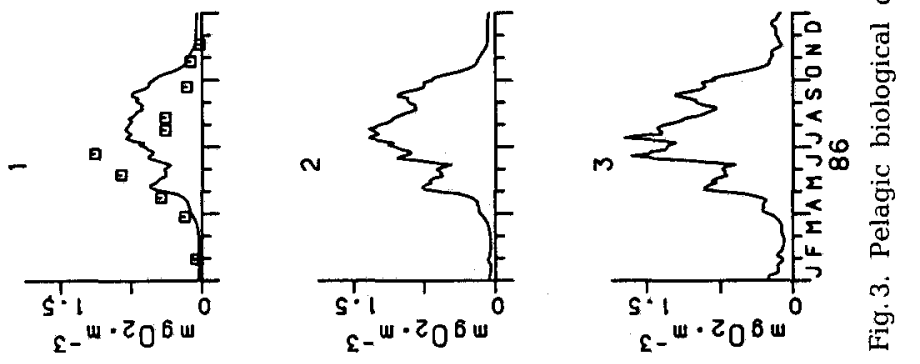


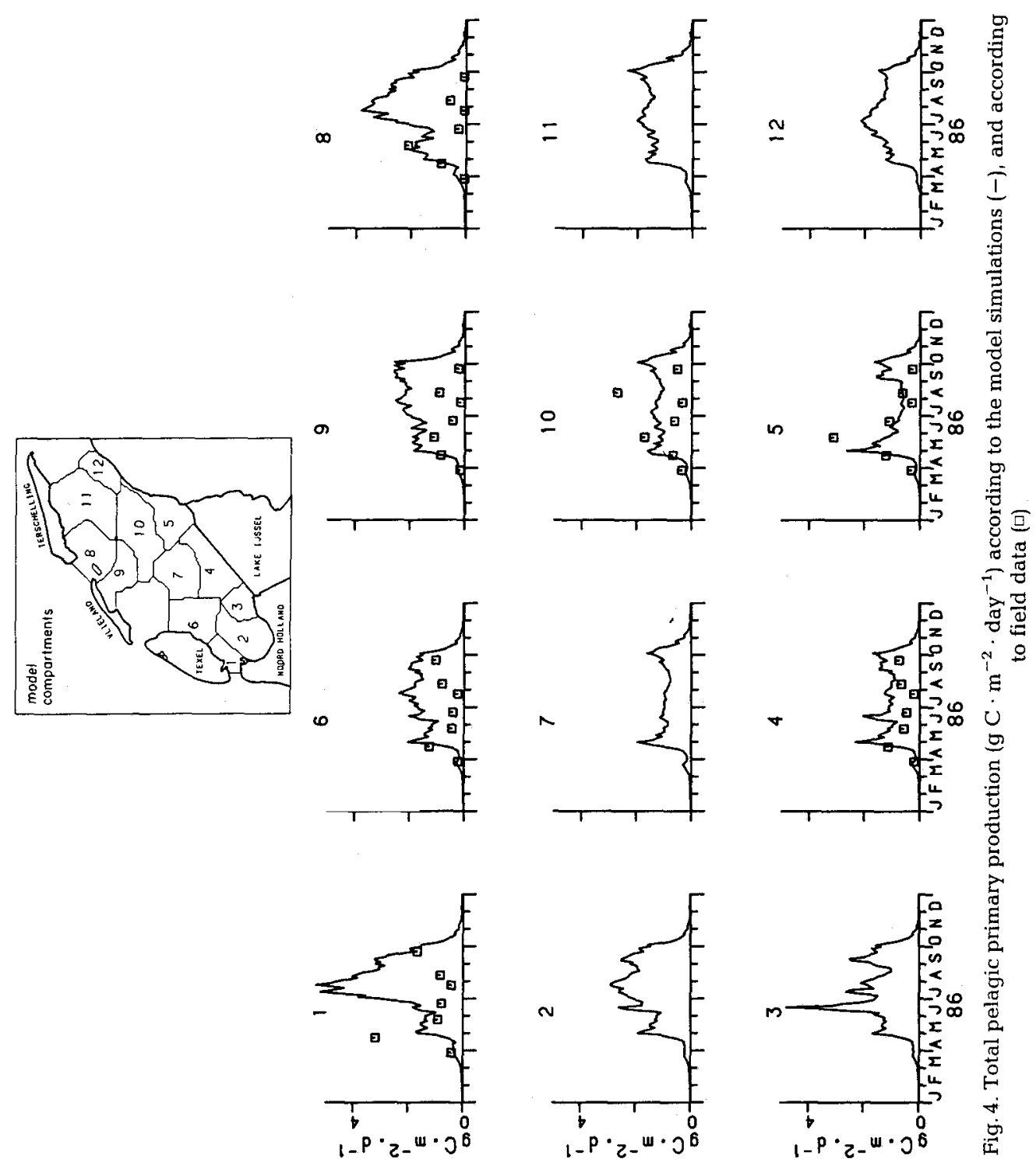


The pelagic submodel was validated for 11 variables, usually in 7 compartments. For each variable, the number of data-points per compartment ranged from 5 to 17 . Examples are given in Figures 2 and 3 for Chl-a and the biological oxygen consumption (BOC), measured in 24- $\mathrm{h}$ incubation tests. Based on all three criteria mentioned above, the Chl-a simulations are reasonable for 2 compartments $(6,9)$ but not for the others, although the annual mean value of the simulation points is almost the same as that of the field data. In the simulation run, the spring bloom starts too early, while too high concentrations are simulated during the period June-September. On the other hand, the simulations of BOC fit the data points adequately. Only in late summer and autumn are oxygen consumptions overestimated. The overall results of the validation of the pelagic submodel points to an adequate simulation of those components whose dynamics are largely determined by transport processes (e.g. phosphate, silicate). However, for almost all variables substantial discrepancies occur between field data and simulations during the second half of the summer-period. Probably, this is due to the absence of nitrogen components in the model, while there are indications that nitrogen rather than phosphorus limits primary production during the third quarter of the year (Helder, 1974; Veldhuis et al., 1988). This effect may be seen most clearly in the overestimation of the total pelagic primary production (Fig. 4).

The benthic submodel is validated for 5 intertidal variables, but there were no field data at hand for the subtidal areas. The validation of this submodel is hampered by the low number of data. Actually, for only 3 to 4 compartments, each having 2-6 data points, could the simulation results be evaluated. The total benthic community respiration on the tidal flats is simulated quite well, with typical maximum values of approximately $1 \mathrm{~g} \mathrm{C} \cdot \mathrm{m}^{-2} \cdot$ day $^{-1}$ in summer, and very low values in winter. The simulations of the higher trophic levels (meiofauna, macrobenthic deposit feeders and suspension feeders) do not agree well with the available field data. The reason for this is not clear.

The submodel concerning the epibenthic processes and variables was validated for the biomass of the macro-epibenthos, for 7 compartments in the intertidal areas and for 5 compartments in the subtidal areas. The number of data points varied between 5 and 20 per compartment. The intertidal biomasses are simulated reasonably well, in some compartments quite well, in others poorly. The simulation of the subtidal macro-epibenthos does not agree with the field data; in all compartments the computed values are

Table 2. Organic carbon budget for the western Wadden Sea for 1986. All entries are expressed in $10^{6} \mathrm{~kg} \mathrm{C}$. a: based on literature data; the transport to the North Sea is the closing entry; b: computed by EMOWAD, the term "rest" includes decrease in biomasses over the year, feeding by birds, etc.

For further details on literature and calculations of the entries see EON-projectgroup (1988)

\begin{tabular}{|lrrrlrrr|}
\hline Input and production & \multicolumn{7}{c}{ Export and consumption } \\
\hline & $\mathrm{a}$ & $\mathrm{b}$ & & $\mathrm{a}$ & $\mathrm{b}$ \\
Discharge Lake IJssel & $135 \pm$ & 5 & 133 & Pelagic mineralization & $270 \pm 80$ & 360 \\
Pelagic pr. production & $310 \pm 95$ & 483 & Benthic mineralization & $210 \pm 95$ & 129 \\
Benthic pr. production & $200 \pm 100$ & 54 & Sedimentation & $5 \pm 5$ & 31 \\
Rest & - & 16 & Export to the North Sea & $160 \pm 185$ & 166 \\
Total & $645 \pm 135$ & 686 & Total & $645 \pm 135$ & 686 \\
\hline
\end{tabular}


much too low. Actually, this is one of the results indicating that the model does not simulate the subtidal processes adequately.

To permit an evaluation of the overall modelling result, the organic carbon budget computed by the model has been compared with a budget obtained from literature data concerning external inputs, primary production, mineralization and sedimentation. It was not possible to estimate the carbon exchange of the western Wadden Sea with the North Sea directly. In the budget based on literature data, this transport term occurs as the closing entry. Consequently, this leads to a large level of uncertainty in the estimation of the transport via both tidal inlets. The conclusions based on the comparison of the two budgets (Table 2) are:

(1) The model computes a much larger pelagic primary production than the literature data suggest. On the other hand, the benthic primary production seems to be underestimated by the model;

(2) According to the model, the pelagic mineralization is approximately $33 \%$ higher than the mineralization estimated from field data. The benthic mineralization, however, seems too low, most probably due to a clear underestimation of the carbon fluxes in the subtidal sediments;

(3) Both budgets indicate a net export of organic carbon from the estuary to the North Sea.

According to the budgets, there is a small difference between the total primary production and the total mineralization in the western Wadden Sea; external input and output seem to have a limited direct importance. From this standpoint, the model outcome agrees well with the literature data. The main discrepancies between the two budgets are the overestimation of the pelagic primary productions, and the underestimation of the benthic mineralization. The absence of nitrogen as potentially limiting nutrient, and the disfunctioning of the model concerning the subtidal areas are probably to a large extent responsible for this lack of agreement. Future development of this model should therefore focus on these aspects.

\section{MODEL APPLICATIONS}

One of the goals of the EMOWAD project was to evaluate to what extent the effects of anthropogenic activities on the functioning of the ecosystem could be indicated using the ecosystem model. However, it must be kept in mind that the model is not suited for an evaluation of all kind of activities. Its potential application is restricted to activities the model can deal with. Furthermore, all output generated by the model simulations is expressed in terms of energy, i.e. organic carbon, which means that only effects on the organic carbon fluxes in the system can be traced. For instance, effects on seal populations, pelagic fish and the accumulation of pollutants cannot yet be considered.

Although a wide range of anthropogenic activities occurs in the Wadden Sea, the examples chosen all deal with large-scale activities which are thought likely to interfere with the main processes. The anthropogenic activities discussed are: (1) Dredging activities; (2) Eutrophication; (3) Commercial mussel culture; (4) Oil spills and other calamities.

Since the effects of changes in anthropogenic activities cannot be compared with actual field data, the model results are evaluated in an indirect way. For each anthropogenic activity, a hypothesis is formulated concerning its impact upon the 
ecosystem. Subsequently, the effects of different levels of activity are simulated and the results are tested against the hypothesis. After a discussion of the effects of the 4 activities, a general evaluation of the applicability of EMOWAD is made. Suggestions are forwarded for further development of the model.

Dredging activities in the western Wadden Sea are sand extraction and spoil disposal of maintenance dredging of harbours and shipping channels throughout the area. Yearly, about 3 million tons of sand (Anonymous, 1981) are extracted and 1 million tons of spoil are disposed of (van Veen, 1988). Both activities affect the sediment load of the water, either by their overflow or by disposal of sediment, and as a result the turbidity of the water is increased, as was observed in the Ems estuary (de Jonge, 1983). This turbidity determines to a large extent the light penetration into the water column and hence the pelagic primary production. Since the relation between light penetration and turbidity in the western Wadden Sea is an inversely exponential one (de Wit et al, 1982), an increase in turbidity will result in a less than proportional decrease in the light penetration. On the other hand, a reduction in turbidity may have a much larger impact. These changes in light penetration might affect the primary production directly, but only during periods when light conditions are the limiting factor, i.e. in spring and autumn. During summer, when nutrient limitation is thought to occur, hardly any changes are expected. The results of the model simulations with a reduced and an increased sediment load of the water show a good correspondence with the hypothesis (Fig. 5). Both the reduction and the increase in turbidity (respectively to 0 and twice the natural concentration), affect the primary production but only in spring and autumn, i.e. the reduction in turbidity results in the largest changes. The maximum production during summer remains about the same in both cases.

Eutrophication of the western Wadden Sea occurs mainly by nutrient loads originating from the river Rhine. A part of these loads reaches the western Wadden Sea via the coastal area of the North Sea, but probably a much larger part enters the estuary via the discharges of Lake IJssel (van der Veer et al., 1989). In the recent past, these discharges have increased considerably: for total $P$ from $0.03 \mathrm{~kg} \cdot \mathrm{sec}^{-1}$ in 1950 to about 0.16 $\mathrm{kg} \cdot \mathrm{sec}^{-1}$ in 1981; and for total $\mathrm{N}$ from about $0.8 \mathrm{~kg} \cdot \mathrm{sec}^{-1}$ in 1950 to about $2.3 \mathrm{~kg} \cdot \mathrm{sec}^{-1}$ in 1981 (van der Veer et al., 1989). The same trend has been observed in the nutrient concentrations in the coastal area of the North Sea (for a review see Brockman et al., 1988). Some changes in the ecosystem have already been observed and suggestions have

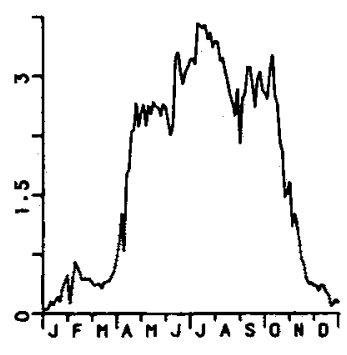

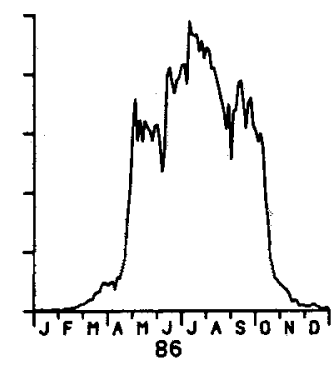

b

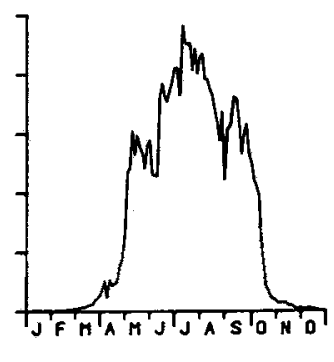

Fig. 5. Total pelagic primary production $\left(10^{6} \mathrm{~kg} \mathrm{C}\right)$ according to the model simulations. a: reduced sediment load; b: standard situation; $\mathrm{c}$ : increased sediment load 
been made that they were the result of eutrophication, e.g. locally low oxygen concentrations (Tijssen \& van Bennekom, 1976; van der Veer \& Bergman, 1986), an increased bloom of the alga Phaeocystis pouchetii (Cadée \& Hegeman, 1986), and an increased biomass and recruitment of macrobenthic animals on the tidal flats (Beukema \& Cadée, 1986). An overall analysis of the impact of eutrophication on the ecosystem is hampered by the fact that the model structure includes only $\mathrm{P}$ and $\mathrm{Si}$ and not $\mathrm{N}$. Changes in nutrient loads are thought to affect the primary production directly but only during periods of nutrient limitation, i.e. the summer period. Main effects are expected in case of a nutrient reduction, since this might prolong the period of nutrient limitation directly. An increase in the loads probably has less effect, since the period of limitation is restricted to 3-4 months in the present situation, and during high production self-shadowing of the algae might become a feed-back mechanism. As a result of the changes in primary production, effects on the macrobenthic biomass might be expected. Since the loads of $P$ and $N$ are partly in the form of organic compounds, a change in these discharges will also affect the input of organic matter. These changes are thought to be compensated for by alterations in the input and output through the tidal inlets. The consequences of a reduced and an increased nutrient load are illustrated in Figure 6 for $\mathrm{PO}_{4}$, and in Figure 7 for the pelagic primary production. Effects on the $\mathrm{PO}_{4}$ concentration in the Wadden Sea occur especially during the first month of the year. The impact on the primary production is visible especially between March and October, the period in which nutrient limitation might occur. Effects also on the benthic community can be observed; either a decrease or increase of macrobenthic animals (Fig. 8). The impact of eutrophication as simulated by the model seems to fit fairly well with the hypothesis formulated.

Mussel culture in the western Wadden Sea started in the 1950s and rapidly increased to a commercial fishery with a yield of up to 100 million $\mathrm{kg}$ a year. Now mussel lots cover an area of about $80 \mathrm{~km}^{2}$ distributed in the subtidal of the whole western Wadden Sea. The mussel Mytilus edulis is one of the dominant species in the subtidal area of the Wadden Sea with a biomass of about $8 \mathrm{~g}$ ash-free dry weight (AFDW) $\cdot \mathrm{m}^{-2}$; on mussel lots their biomass increases by a factor of $30-40$ to about $260 \mathrm{~g} \mathrm{AFDW} \cdot \mathrm{m}^{-2}$ (Dekker, 1987).

At present, there is no insight into the impact of mussel culture on the ecosystem in the Wadden Sea. Recently, van der Veer (1989) postulated that under the assumption of a food limitation of the benthos in the Wadden Sea, the introduction of commercial mussel culture in the past might have resulted in a reduction of the other macrobenthic animals, especially on the tidal flat systems. In their present form, the model simulation results in a far too low macrobenthic biomass in the subtidal, compared with field data. Therefore, the impact of the mussel culture cannot be evaluated. An indirect approach for testing the hypothesis of van der Veer (1989) is the introduction of extra biomass in the sublittoral and the analysis of the effects on the macrobenthic biomass in the intertidal zone. As a result of the malfunctioning of the subtidal model the initially higher biomass values diminish to low levels again within a year (Fig.9). Additionally, the impact on the intertidal is too small to have any affect on the macrobenthos. Therefore, the impact of mussel culture cannot be adequately evaluated at present.

Oil spills and other calamities in or near the Wadden Sea can result in a large-scale pollution of the area, especially of the benthic community in the intertidal area (Bergman, $1982,1983)$. Since these macrobenthic animals are important as food source for wading. 


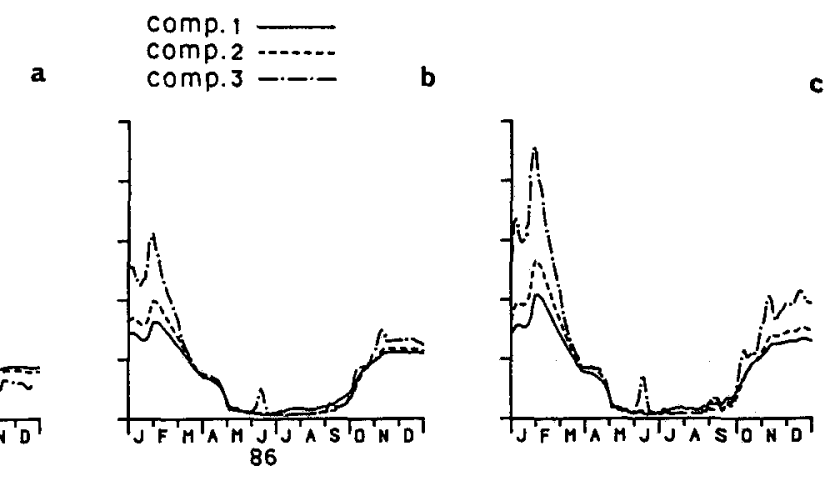

Fig. 6. Concentrations of soluble reactive phosphate $\left(\mathrm{mmol} \cdot \mathrm{m}^{-3}\right)$ in the compartments $1,2,3$ according to the model simulations. a: no discharge of total P (TP) from Lake IJssel; b: standard situation; $\mathrm{C:}$ TP discharges 1.5 times as large as the standard situation
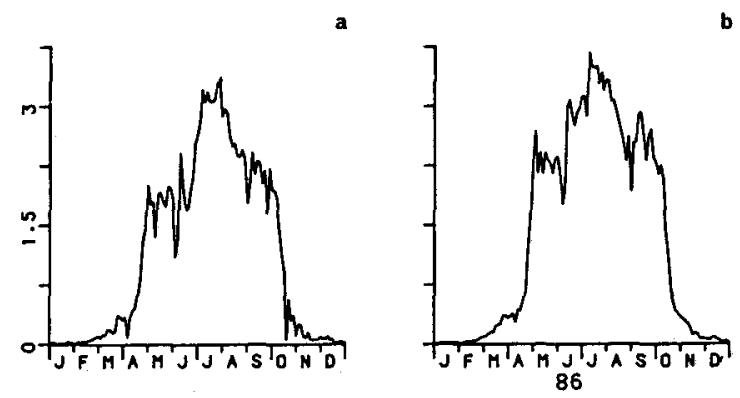

b

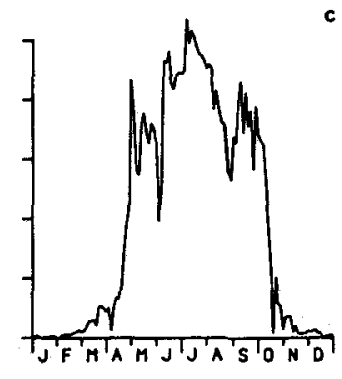

Fig. 7. Total pelagic primary production $\left(10^{\circ} \mathrm{kg} \mathrm{C}\right)$ simulated with a TP and Si load from Lake IJssel equal to 0 (a), the standard situation (b), 1.5 times as large as the standard situation (c)
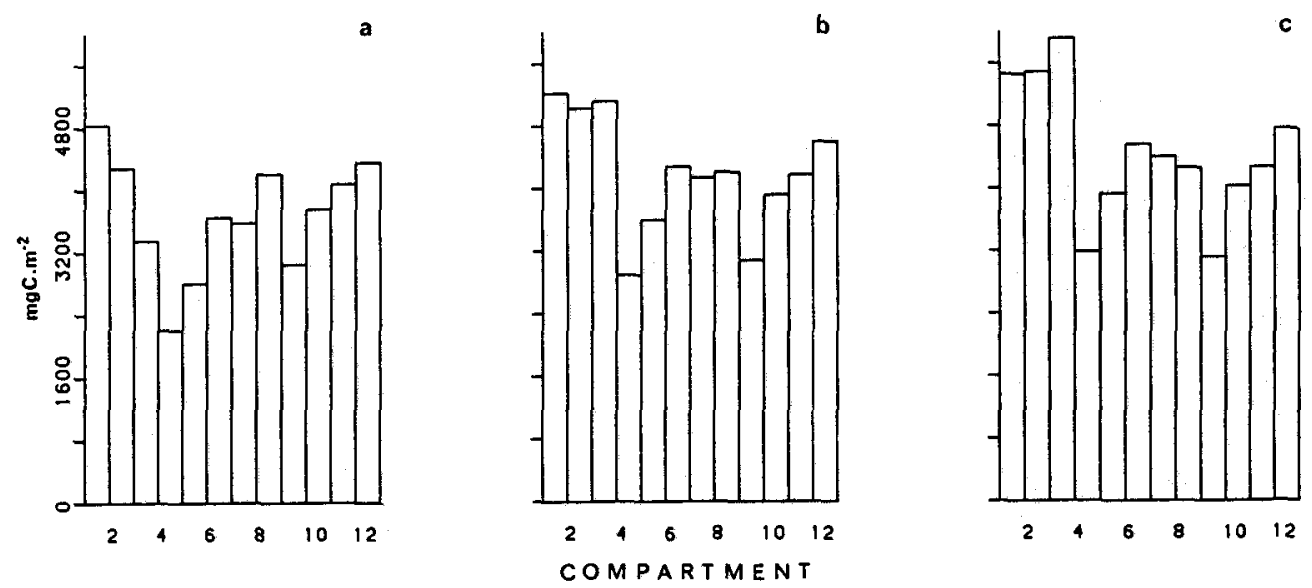

Fig. 8. Mean biomass of benthic suspension feeders in the intertidal $\left(\mathrm{mg} \mathrm{C} \cdot \mathrm{m}^{-2}\right)$ in the various compartments in April-September simulated with a TP and Si load from Lake IJssel equal to 0 (a), the standard situation (b), 1.5 times as large as the standard situation (c) 


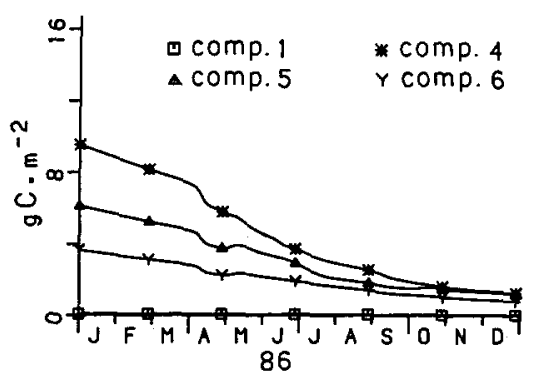

Fig. 9. Biomass of benthic suspension feeders in the subtidal $\left(\mathrm{g} \mathrm{C} \cdot \mathrm{m}^{-2}\right)$ in compartments $1,4,5$ and 6 with increased initial values on January 1

birds (Smit \& Wolff, 1983) and juvenile stages of commercially important fish species (Zijlstra, 1972), such a calamity might have an enormous effect on the functioning of the area for these animals. In case of an elimination of the macrobenthic community, recolonization will occur either by new recruitment of juveniles or by immigration of adults. The time span necessary for recovery is thought to be fairly short, i.e. a few years (van der Veer et al., 1985). The exact initial response will depend on the time of occurrence, since recruitment is restricted to certain periods of the year. Therefore, the pattern of recolonization is simulated for two situations: a reduction in January and one in May, during the period of recruitment. It is thought that in the latter case recolonization starts immediately, but at a lower rate due to the destruction of most animals during spawning. A reduction on 1 January results in immigration before the period of recruitment and makes a larger recruitment possible. In the model, recolonization of the epibenthic predators takes place-by immigration from the North Sea, while the benthic suspension feeders can only grow from the existing biomass. Still, the above hypothesis is reflected in the model results, which in both situations show a recovery from May onwards. After a reduction on January 1, biomasses at first continue to decrease, following the natural seasonal pattern (Fig. 10). In both cases, recovery occurs within a year. Severe effects on the epibenthic predators are only observed after a reduction in May. These results fit fairly well with the expectations.

In conclusion, it can be stated that the western Wadden Sea model is in general a useful tool in evaluating the impact of certain anthropogenic activities in the area. However, the functioning of the subtidal part of the model should be improved as soon as possible and, furthermore, the model structure should be extended by an incorporation of the N cycle. Finally, it must be kept in mind that EMOWAD, which only gives a general description of the ecosystem, can never be applied to specific topics without exact definition of its specific processes.

\section{CONCLUSIONS}

The construction, validation and application of the new model of the western part of the Dutch Wadden Sea (EMOWAD) lead to the following conclusions:

- The use of a detailed hydrodynamical model in constructing the transport part of the ecological model gives good results.

- The model gives reasonable results for more than half of the variables validated. 

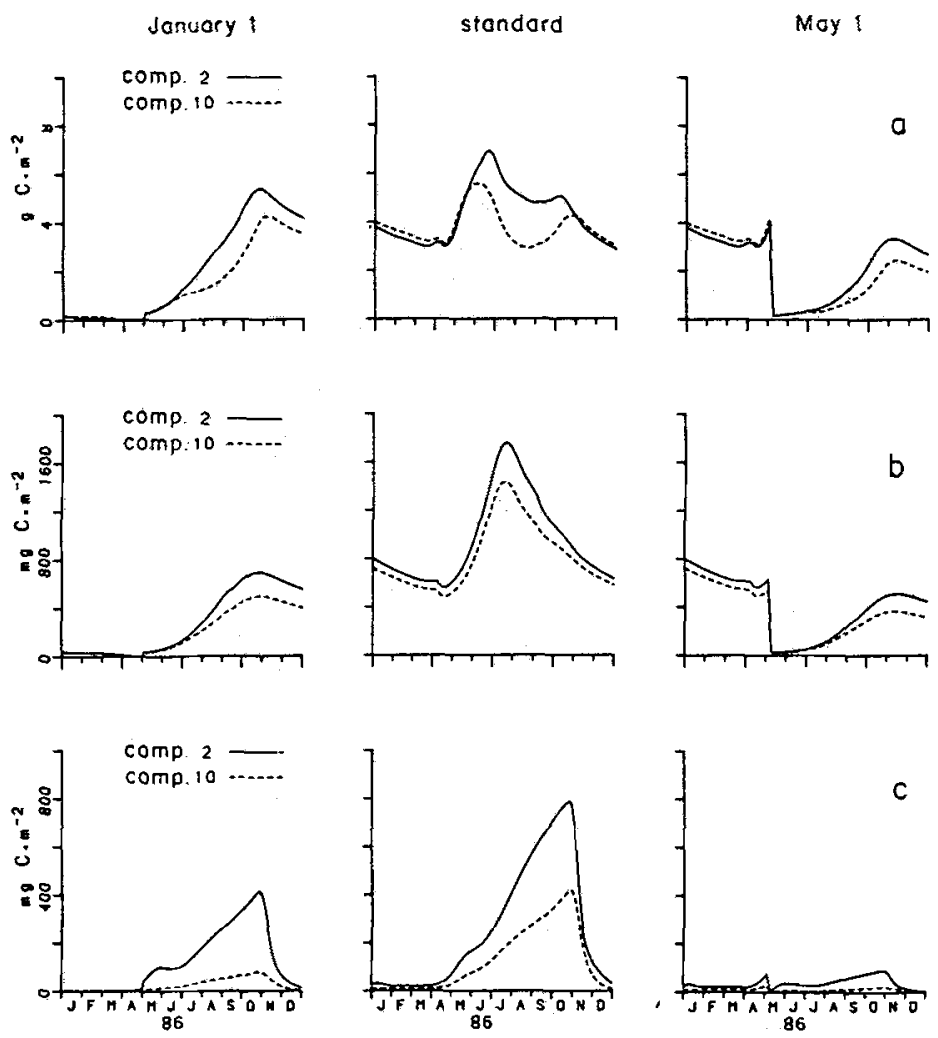

Fig. 10. Biomass in the intertidal in compartments 2 and 10 of a: benthic suspension feeders; b: benthic deposit feeders and $\mathrm{c}$ : epibenthic predators simulated with a reduction of the (epi)benthic system by $95 \%$ on January 1 (left) and May 1 (right) compared with the standard model (middle)

- The pelagic primary production is overestimated in the model. On the other hand, the benthic production is underestimated.

- The benthic and epibenthic system in the sublittoral functions insufficiently in the present model. However, a model version with higher food availability for benthic organisms in the sublittoral area shows an improvement.

- In principle EMOWAD is a useful tool in answering certain management questions.

Models can be very useful to set up and guide monitoring programmes:

- A model can guide monitoring research and indicate parameters which should be measured and at what frequencies.

- A model may structure the storage of chemical and biological data sets. Often, it is difficult to establish the format in which, for example, biological data should be stored. A mathematical model can serve as an intermediate in storing data of different scientists and disciplines in more accessible forms.

- Monitoring data can feed models. On the one hand, modellers need data (boundary conditions, forcing functions) to make model runs for certain years; on the other hand, managers would like to be able to combine the information obtainable from different data sets. In the future, the models may be used to achieve this goal. 
Nevertheless, when further applications of EMOWAD are made, it is recommended to:

- Analyse the model formulation of the pelagic primary production, including limiting factors. When eutrophication problems are involved, a nitrogen module should be constructed.

- Improve the functioning of the sublittoral model. Special attention should be paid to the possibility of including different amounts of mussel biomasses in different model runs in order to study the impact of these biomasses on the rest of the ecosystem.

- Create, in cooperation with the environmental management of the Wadden Sea, a discussion and working group around the model instrument to generate relevant management questions and to make the model more accessible to possible users. Because of the complexity of ecosystem models, the latter can only be achieved by an active participation of the management in model building projects.

\section{LITERATURE CITED}

Anonymous, 1981. Zandwinning in de Waddenzee. Rijkswaterstaat Directie Friesland, Leeuwarden, $48 \mathrm{pp}$.

Baretta, J. W. \& Ruardij, P., 1988. Tidal flat estuaries (simulations and analysis of the Ems estuary). Springer, Heidelberg, 353 pp.

Bergman, M. J. N., 1982. Gedrag, bestrijding en biologische effecten van olie in estuariene gebieden. I. Literatuuroverzicht. - RIN-Rapp. 82-18, 1-420.

Bergman, M. J. N., 1983. Gedrag, bestrijding en biologische effecten van olie in estuariene gebieden. II. Olie in de Waddenzee. - RIN-Rapp. 83-22, 1-97.

Beukema, J. J. \& Cadée, G. C., 1986. Zoobenthos responses to eutrophication of the Dutch Wadden Sea. - Ophelia 26, 55-64.

Brockman, U., Billen, G. \& Gieskes, .W. W. C., 1988. North Sea nutrients and eutrophication. In: Pollution of the North Sea. Ed. by W. Salomons, B. C. Bayne, E. Duursma \& U. Förstner. Springer, Berlin, 348-389.

Cadée, G. C. \& Hegeman, J., 1986. Seasonal and annual variation in Phaeocystis pouchetii (Haptophyceae) in the westernmost inlet of the Wadden Sea during the 1973 to 1985 period. Neth. J. Sea Res. 20, 29-36.

Dekker, R., 1987. The importance of the subtidal macrobenthos as food source for the Wadden Sea ecosystem. In: Proceedings of the 5th International Wadden Sea Symposium. Ed. by S. Tougaard \& S. Asbrik. National Forest and Nature Agency \& Museum of Fishery and Shipping, Esbjerg, $27-36$.

EON-projectgroup, 1988. Ecosysteemmodel van de westelijke Waddenzee. - NIOZ-Rapp. 1988-1, $1-88$.

Helder, W., 1974. The cycle of dissolved inorganic nitrogen compounds in the Dutch Wadden Sea. Neth. J. Sea Res. 8, 154-173.

Jonge, V. N. de, 1983. Relations between yearly dredging activities, suspended matter concentrations, and the development of the tidal regime in the Ems estuary. - Can. J. Fish. aquat. Sci. 40, 289-300.

Raaphorst, W. van., Ruardij, P. \& Brinkman, A. G., 1988. The assessment of benthic phosphorus regeneration in an estuarine ecosystem model. - Neth. J. Sea Res. 22, 23-36.

Ridderinkhof, H., 1988. Tidal and residual flows in the western Dutch Wadden Sea. I. Numerical model results. - Neth. J. Sea Res. 22, 1-21.

Smit, C. J. \& Wolff, W. J., 1983. Birds of the Wadden Sea. In: Ecology of the Wadden Sea. Ed. by W. J. Wolff. Balkema, Rotterdam, 2, 6/1-6/308.

Tijssen, S. B. \& Bennekom, A. J. van, 1976. Lage zuurstofgehaltes in het water op het Balgzand. $\mathrm{H}_{2} \mathrm{O} 9,28-31$.

Veen, M. van, 1988. Inventarisatie baggeractiviteiten directie Friesland 1975-1987. Rijkswaterstaat Directie Friesland, Leeuwarden $A N W-8810$. 
Veer, H. W. van der, 1989. Eutrophication and mussel culture in the western Dutch Wadden Sea: impact on the benthic ecosystem, a hypothesis. - Helgoländer Meeresunters. 43, 517-527.

Veer, H. W. van der \& Bergman, M. J. N., 1986. Development of tidally related behaviour of a newly settled 0-group plaice (Pleuronectes platessa) population in the western Wadden Sea. - Mar. Ecol. Prog. Ser, 31, 121-129.

Veer, H. W. van der, Bergman, M. J. N. \& Beukema, J. J., 1985. Dredging activities in the Dutch Wadden Sea: effects on macrobenthic infauna. - Neth. J. Sea Res. 19, 183-190.

Veer, H. W. van der, Raaphorst, W. van \& Bergman, M. J. N., 1989. Eutrophication of the Dutch Wadden Sea: I. Nutrient loadings of the Marsdiep and Vliestroom basins. Helgolander Meeresunters. 43, 501-515.

Veldhuis, M. J. W., Colijn, F, Venekamp, L. A. H. \& Villerius, L., 1988. Phytoplankton production and biomass in the western Wadden Sea (The Netherlands): a comparison with an ecosystem model. - Neth. J. Sea Res. 22, 37-49.

Wit, J. A. W. de, Schotel, F. M. \& Bekkers, L. E. J., 1982. De waterkwaliteit van de Waddenzee 1971-1981. - RIZA Nota 82-065, 1-67.

Zijlstra, J. J., 1972. On the importance of the Wadden Sea as a nursery area in relation to the conservation of the southern North Sea fishery resources. - Symp. zool. Soc. Lond. 29, 233-258. 